\title{
Mini Review \\ Food and Nutrition Situation in a Resource Limited Country - A Literature Review of the Last Decade in Uganda
}

\author{
Peter Milton Rukundo*
}

Kyambogo University Department of Human Nutrition and Home Economics, Kampala, Uganda

"Corresponding author: Peter Milton Rukundo, Kyambogo University Department of Human Nutrition and Home Economics, Kampala, Kyambogo University Post Box 1, Uganda, Tel: +256782425076; E-mail: rukpeter@hotmail.com

\begin{abstract}
Uganda is ranked among the high malnutrition burdened countries. Two successive Demographic and Health Surveys (UDHS) in 2006 and 2011 revealed that malnutrition affects atleast one of every five persons in the population. This paper has used literature review techniques to comprehend the situation of food and nutrition security in Uganda. The analysis has taken into account DHS results, food insecurity reports, cost of hunger studies and nutrition profiles reports with complementation from other published literature related to food and nutrition security in Uganda. From the analysis of 28 publications cited by this study, it is apparent that malnutrition remains to be a persistent problem in the country. Childhood stunting, a devastating indicator of chronic malnutrition, affects $33 \%$ of children aged 6 - 59 months while an estimated $26 \%$ of the population is at risk of undernourishment due to food insecurity. Despite the absence of reliable estimates on micronutrient deficiencies, anaemia and vitamin A deficiency are a challenge among some of the vulnerable population groups. Within the last decade, Vitamin A deficiency is estimated to have affected over a quarter of children and women of reproductive age, while anaemia affects about 5 of every 10 children aged 6 - 59 months and about 1 in 4 of women of reproductive age. Malnutrition and related deprivation have been associated with failure to ensure adequate dietary intake in infancy and childhood, inadequate intake of especially animal sourced foods, poor micronutrient intake, and socio-economic constraints on the household among others. Moreover, the costs of malnutrition on the economy are an apparent latent challenge as an estimated 5\% of the Gross Domestic Product (GDP) is being lost due to combined effects of stunting and other consequences of undernutrition. It is of the essence that nutrition specific and nutrition sensitive interventions are financed as strategic national development investments given the implications of nutrition on sustainable human and economic development.
\end{abstract}

Received Date: May 24, 2016

Accepted Date: August 16, 2016

Published Date: August 22, 2016

Citation: Rukundo, P.M. Food and nutrition situation in a resource limited country - a literature review of the last decade in Uganda. (2016) Int J Food Nutr Sci 3(4): 1- 5.

DOI: $10.15436 / 2377-0619.16 .944$

Keywords: Food and nutrition security; Socio-economic development; Uganda

\section{Introduction}

Food security and nutrition are closed intertwined concepts that relate mutually in any setting and at any level of development policy and programming. They all require a multi-sectoral and multi-disciplinary approach and they are associated to the extent that food insecurity will translate into various forms of malnutrition based on the extent of exposure ${ }^{[1]}$. It also seems apparent that food security is necessary but not sufficient to guarantee good nutrition: while food may be readily availability and accessible it may not be utilised and maintained in a balanced and adequate diet within a healthy environment where care for all is adequate ${ }^{[2]}$.

Evidence now suggests that estimated $45 \%$ of under-five mortality in the world is attributable to undernutrition and the problem is more pronounced in Sub-Saharan African countries ${ }^{[3,4]}$. There is now a linkage between improved nutrition and economic performance in the context of Gross Domestic Product (GDP). Improvement in economic performance of GDP has shown too often translate into increased economic potential of the citizenry to access diverse food and nutritional information thereby reducing un- 
dernutrition related indices in progressive countries in sub-Saharan Africa ${ }^{[5]}$.

Despite the impressive economic progress that has translated in growth of the economy and poverty reduction in Uganda, the modest progress needs to be accelerated given that the country is still a high malnutrition-burdened country; it is categorised among the 34 countries that account for $90 \%$ of the global burden of malnutrition ${ }^{[6]}$. Stunting is at more than $33 \%$ in children under five years of age hence the risk of poor mental and cognitive development in the future ${ }^{[7]}$. Micronutrient deficiencies are also a problem in the country. Anaemia, characterised by low levels of the iron-rich oxygen carrier pigment called haemoglobin, is among the leading factors associated with mortality in the country and affects $31 \%$ of pregnant women, $22 \%$ of non-pregnant women and $49 \%$ of children under five years ${ }^{[7,8]}$. In addition, one third of children are affected by Vitamin A deficiency ${ }^{[9]}$. In effect, malnutrition contributes to a loss of about $4 \%$ of the Gross Domestic Product (GDP) every year ${ }^{[10]}$.

This paper reviews the available evidence on the food and nutrition security in Uganda to argue that investment in the improvement in nutrition, especially among women of reproductive age and children, has significant economic benefits that can boost human productivity and development in a resource limited setting.

\section{Literature review}

This paper has used literature review techniques and triangulation to comprehend the situation of food and nutrition security in Uganda. More specifically, the review analysed national Demographic and Health Surveys (DHS) results, food insecurity reports, cost of hunger studies and nutrition profiles reports. In addition, online resources especially the PubMed and Google Scholar data-bases were searched up to April 2016. The search terms emphasised included: "food insecurity"; "nutrition"; "malnutrition" and a composite term "food and nutrition in Uganda". Whereas over 100 hits were received, detailed profiling of the searched data narrowed to 28 publications that have been cited. However, further scrutiny established 9 key studies that had looked at food security and nutrition in Uganda between the periods 2002 - 2015. Other relevant secondary data were also sourced and used in this review. The Table 1 below summarises the studies on food and nutrition security in Uganda.

Table 1: Studies that have looked at food and nutrition security in Uganda, 2002-2015.

\begin{tabular}{|l|l|l|l|l|}
\hline Author & Publication type & Subject investigated & Methodology used & Main findings \\
\hline $\begin{array}{l}\text { Bachou and } \\
\text { Labadarios (2002) }\end{array}$ & Journal: Nutrition & $\begin{array}{l}\text { Childhood nutrition indica- } \\
\text { tors }\end{array}$ & Review & Stunting affecting over 40\% in children \\
\hline $\begin{array}{l}\text { Benson, Mugarura } \\
\text { and Wanda (2008) }\end{array}$ & $\begin{array}{l}\text { Journal: Agriculture } \\
\text { Economics }\end{array}$ & Impact of rising food prices & Impact analysis & $\begin{array}{l}\text { Rising food prices affected the ability of } \\
\text { to eat a diversified diet }\end{array}$ \\
\hline FANTA (2010) & Report & $\begin{array}{l}\text { Food and nutrition situation } \\
\text { analysis }\end{array}$ & $\begin{array}{l}\text { Situation analysis } \\
\text { review }\end{array}$ & $\begin{array}{l}\text { Pockets of food insecurity were persistent } \\
\text { in the country. Stunting was affecting } \\
35 \% \text { of the children } 6-59 \text { months }\end{array}$ \\
\hline $\begin{array}{l}\text { Harvey, Rambeloson } \\
\text { and Dary (2010) }\end{array}$ & Report & $\begin{array}{l}\text { Dietary patterns of women } \\
\text { and children }\end{array}$ & Cluster survey & $\begin{array}{l}\text { Variations dietary patterns among urban } \\
\text { and rural folk }\end{array}$ \\
\hline UBOS (2007) & Report & $\begin{array}{l}\text { Demographic and health } \\
\text { indicators }\end{array}$ & Cluster survey & $\begin{array}{l}\text { Stunting was affecting 38\% of children } \\
6-59 \text { months old }\end{array}$ \\
\hline UBOS (2012) & Report & $\begin{array}{l}\text { Demographic and health } \\
\text { indicators }\end{array}$ & Cluster survey & $\begin{array}{l}\text { Stunting had reduced to 33\% in children } \\
6-59 \text { months old }\end{array}$ \\
\hline UBOS (2013) & Report & Vitamin A analysis & $\begin{array}{l}\text { Laboratory analy- } \\
\text { sis of survey data }\end{array}$ & $\begin{array}{l}\text { Vitamin A affected 33\% of children } 6 \text { - } \\
59 \text { months old }\end{array}$ \\
\hline $\begin{array}{l}\text { AUC, UNECA and } \\
\text { WFP (2013) }\end{array}$ & Report & Cost of hunger & Model analysis & $\begin{array}{l}\text { Up to 5\% of Uganda's GDP lost annually } \\
\text { due to childhood undernutrition }\end{array}$ \\
\hline $\begin{array}{l}\text { Namugumya et al. } \\
\text { (2014) }\end{array}$ & Report & $\begin{array}{l}\text { Estimates of the cost of mal- } \\
\text { nutrition to support advocacy }\end{array}$ & Profiles analysis & $\begin{array}{l}1 \text { million children in Uganda at risk of } \\
\text { permanent disability due to stunting }\end{array}$ \\
\hline
\end{tabular}

Available literature showed that two studies by had used literature analysis to report the situation of food and nutrition ${ }^{[10,11]}$. In both studies, the Uganda Demographic and Health Survey (UDHS) was the primary source of the literature. In addition, three national surveys were undertaken in the last decade, two being UDHS ${ }^{[7,9]}$ and the third being national food consumption survey that was meant to understand dietary patterns for women and children ${ }^{[12]}$. The other three studies considered in this study involved costing hunger using scenario models $\mathbf{S}^{[13]}$, profiling nutrition to establish economic and productivity losses attributed to poor nutrition especially stunting and iron deficiency ${ }^{[8]}$. An impact assessment has also been performed to establish the impact of food prices on dietary choices and preferences in Uganda ${ }^{[14]}$.

\section{Conceptual framework}

The conceptual framework adopted in this paper highlights a pathway from stable agriculture and food production to sustainable development. It supposes that stable agriculture has potential to stabilise food prices and market forces hence resulting in household food security, income security and diet diversity. As a result, good nutritional status and reduced disease burden can be achieved if there is increased nutrition knowledge and awareness, improved nutritional practices, maintenance of good sanitation practices and promotion of physically active and healthy lifestyles. This has potential to lead to an enhanced public health care system with nutritionally sensitive primary health care that sustains an active and productive population, hence a less burdened economy. Consequently, sustainable and equitable development can be gradually achieved with modest economic implications. 


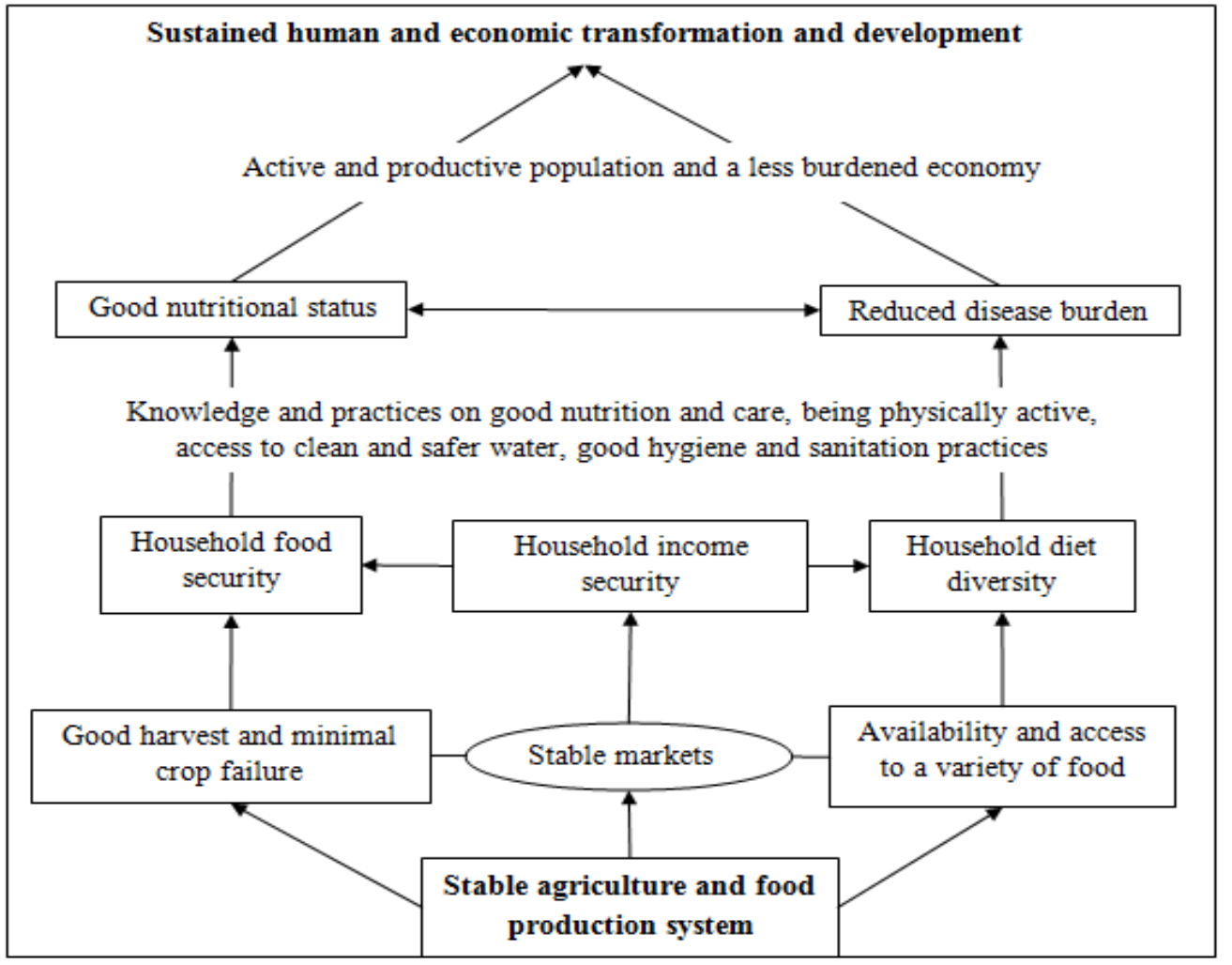

Figure 1: Conceptual pathway linking food and nutrition to sustainable human development.

\section{The situation of food insecurity and malnutrition in Uganda}

Food insecurity: Food security is a multi-dimensional phenomenon for which several definitions exist. The World Food Summit in 1996 defined food security as existing when all people at all times have physical and economic access to sufficient, safe and nutritious food to meet their dietary needs and food preference requirements for an active and healthy life. On the contrary, food insecurity exists when people lack secure access to sufficient amounts of safe and nutritious food for normal growth and development ${ }^{[15]}$.

Despite the consensus on the description of food security, the indicators for measuring food insecurity vary and there seems to be no universal gold standard to this intriguing global problem ${ }^{[16]}$. In addressing this challenge, the Food and Agriculture Organization of the United Nations (FAO), and its partners, annually present reports on the State of Food Insecurity in the World; also referred to as SOFI reports. They use a composite hunger outcome of undernourishment, defined as the prolonged inability to acquire enough food that meets the dietary energy requirement, to report food insecurity. This phenomenon is derived from a suite of food insecurity indicators built from the dimensions of food availability, access, stability and utilisation. In 2015, the report indicated that nearly 800 million people were estimated to be facing hunger globally. In Africa, more than 230 million are suffering from this scourge ${ }^{[17]}$.

In Uganda, food insecurity has been a problem in many parts of the country. Estimates in 2015 showed that $26 \%$ of the population is facing undernourishment, equivalent to over 10 million people ${ }^{[17]}$. While disaggregated sub-national data on food insecurity is absent, improvements in food insecurity have been sub-optimal. In effect, the populations of the undernourished seem to have been slowly increasing since 2001 (Figure 2), a phenomenon attributed to the high population growth rate at just over $3 \%{ }^{[10,18]}$. The highest levels of food insecurity have been witnessed in the North-Eastern region of Karamoja; affecting over one-third of the population suffering cyclic food insecurity annually ${ }^{[10]}$. The 2014 National Housing and Population Census also revealed that majority of Ugandans were consuming a sub-optimal number of meals per day; an estimated $51.4 \%$ had consumed two meals, while $12 \%$ had consumed only one meal, with the problem being more pronounced in the rural areas ${ }^{[18]}$.

Malnutrition outcomes in the country: Although Uganda produces adequate food to feed her population, the country is still ranked among the countries that are heavily burdened by undernutrition ${ }^{[19]}$. As shown in Figure 2, three successive Uganda Demographic and Health Surveys (UDHS) have showed that undernutrition affects about one of every five people, while childhood stunting, a devastating indicator of chronic under-nutrition, affects over $30 \%$ of children aged $6-59$ months $\mathbf{s}^{[7,20]}$. Despite the absence of reliable estimates on micronutrient deficiencies, anaemia affects $49 \%$ of children and $31 \%$ of pregnant women ${ }^{[7]}$. On the hand vitamin deficiency affects more than $33 \%$ of children 6 - 59 months thereby increasing their risk to early blindness and poor immunity to disease $\mathrm{e}^{[9]}$. 


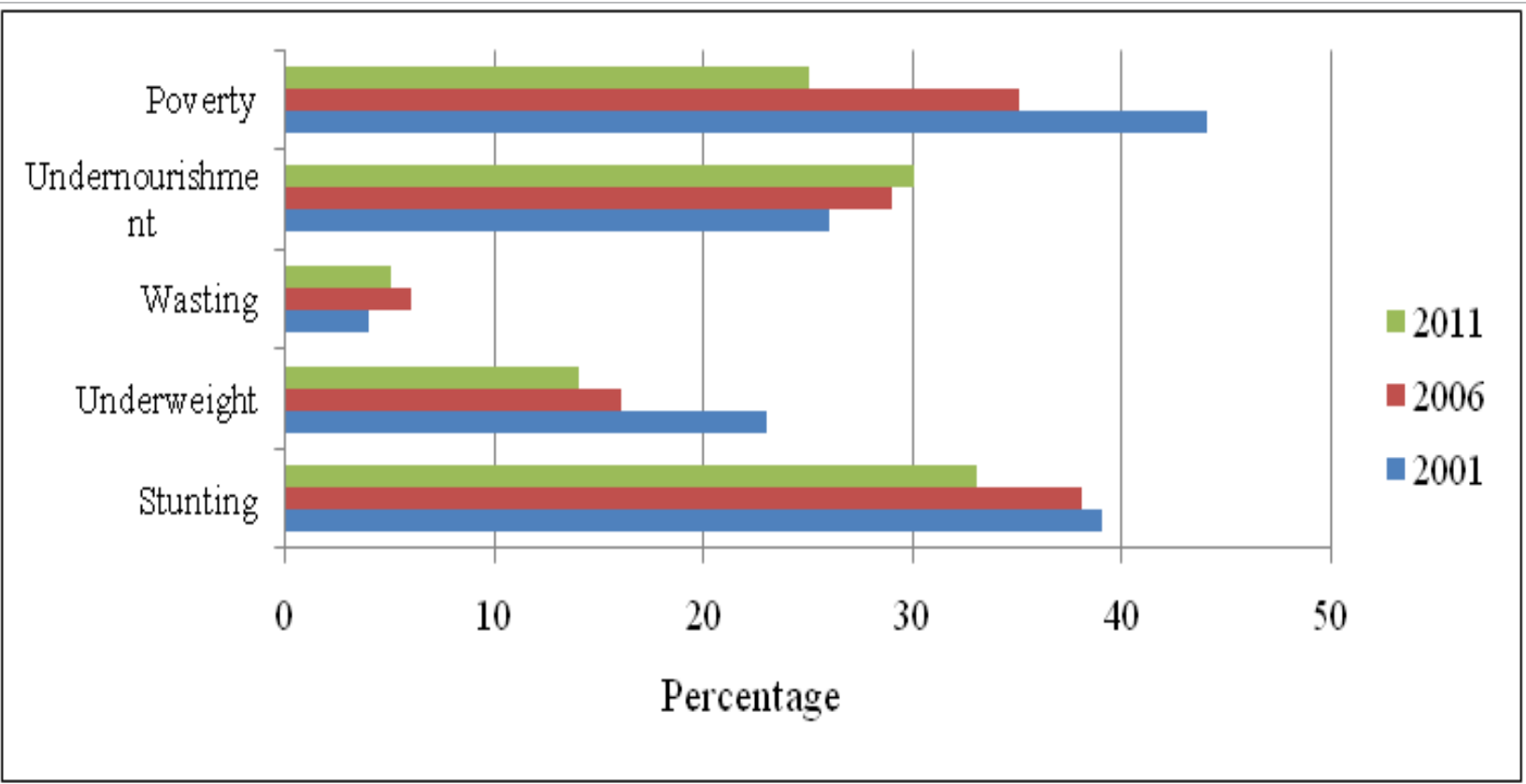

Figure 2: Trends in poverty, undernourishment and undernutrition indicators in Uganda

Source: FAO (2013), MFPED (2013) and UBOS (2012).

Despite improvements in the levels of poverty from $44 \%$ to $25 \%$ over the last decade ${ }^{[21]}$, there have been minimal gains in the improvement of nutritional related indicators, especially stunting which still affects over one third of children 6 - 59 months ${ }^{[7]}$. Moreover, the absolute number of those affected by hunger and undernourishment has also been slowly increasing ${ }^{[17,22]}$ due to arapidly increasing population at a rate over $3 \%$ in the last decade ${ }^{[18]}$.

The problem undernutrition in the country has been associated with among others, the failure to ensure adequate dietary intake in infancy and childhood ${ }^{[23-25]}$, inadequate intake of high biological value protein and micronutrients especially from animal sources ${ }^{[12,24]}$, household socio-economic constraints ${ }^{[7,26]}$ and disaster-related shocks ${ }^{[10,25]}$. The problem is increasing becoming evident in low income rural and urban areas and among young adults ${ }^{[27]}$.

In this era of globalisation, the surge in nutrition-related non-communicable disease cannot be under looked. Overweight, obesity and diabetes affect $18.6 \%, 3.9 \%$ and $2.8 \%$ of the population respectively, with women being the most affected ${ }^{[28]}$. In the South of the country, a recent study revealed the prevalence of overweight and obesity in adolescentsat $7 \%$ and $1 \%$ respectively, while adult obesity was estimated at $5 \%$, raised blood pressure at $49 \%$, raised blood sugar at $7 \%$ and raised blood cholesterol at $22 \%{ }^{[5]}$. These numbers point to potential problem of an over-burdening health care budget. Increased investment in improvement of nutritional awareness will be vital in sustaining healthy food and lifestyle choices to mitigate the risk of malnutrition and associated non-communicable diseases.

\section{The burden of malnutrition on Uganda's economy and pro- ductivity}

Malnutrition indicators have led to poor human development ranking of many countries ${ }^{[4]}$. Poor nutrition in women and children has also been associated with impaired physical and mental development, low productivity and low earnings, chronic fatigue, depleted care giving abilities, and adult onset of non-communicable chronic diseases among others ${ }^{[3]}$.

A Cost of Hunger $(\mathrm{COH})$ study in Uganda that was commissioned by the African Union ${ }^{[13]}$ did reveal that $15 \%$ of child mortality cases in the country were linked to malnutrition, and as many as $82 \%$ of the cases of childhood undernutrition go untreated by the health care system. Moreover, they deduced that $54 \%$ of the adult population had suffered from stunting as children. Based on 2009 estimates, the study placed the annual cost associated with childhood undernutrition and hunger at an equivalent of 5.6\% of the Gross Domestic Product (GDP).

More recently in 2014, Namugumya et al. ${ }^{[8]}$ profiled the burden of malnutrition in Uganda. They showed that the country might incur a loss equivalent to Uganda shillings 19 trillion - equivalent to 7.7 billion United States dollars of economic productivity, and over one million children will have permanent disabilities, if the current stunting levels are not reduced by the period 2013 - 2025. In effect, their scenario analysis projects that investing in the improvement of young child and maternal nutrition in Uganda has a potential to increase national economic productivity in terms of physical and intellectual output. In essence, every 1,000 shillings (about 30 cents of USD) invested in nutrition has potential economic benefits that are at least six times more. Moreover, the country would save more than 110,000 lives if the country invested to mitigate the current malnutrition levels in the next $8-10$ years.

\section{Conclusion}

Information on the situation of food and nutrition security and its impacts in Uganda is still limited and slowly evolving but the price of malnutrition is too high to bear. Despite the modest gains in economic growth and poverty reduction, the pace at which food insecurity and malnutrition are reducing are still minimal and they continue to impede on the economy. Suffice to mention that the country is endowed with a beautiful landscape that supports all year round agriculture and food production. What is required is re-organisation of strategy to increase priority 
investment not only in commercial and mechanised agriculture, but also boosting diverse food production and consumption, improved maternal and child care, increased nutritional awareness, and improvement in technology and nutritional-value addition of indigenous food varieties, among others.

Existing levels of malnutrition also have implication on public health policy. Multi-sectoral nutrition interventions that connect agriculture, health and rural development, need to be positioned in public health activities of health promotion, disease prevention and interventions at all levels. Actors need to appreciate the potential of good nutrition in the acceleration of equitable and sustainable socio-economic transformation and human development. In effect, accelerated nutrition investment is a vital requirement that will spur Uganda into a middle income economy. Time is of the essence in mitigation of malnutritionand its ills in this country which is not limited by resources but their exploitation.

\section{References}

1. Barrett CB (2010) Measuring food insecurity. Science327, 825-828. 2. Dilley M, Boudreau TE (2001) Coming to terms with vulnerability: a critique of the food security definition. Food Pol 26, 229-247.

3. Black RE, Allen LH, Bhutta ZA et al. (2008) Maternal and child undernutrition: global and regional exposures and health consequences. Lancet 371, 243-260.

4. Black RE, Victora CG, Walker SP et al. (2013) Maternal and child undernutrition and overweight in low-income and middle-income countries. Lancet 382, 427-451.

5. IFPRI (2014) Global Nutrition Report 2014: Actions and Accountability to Accelerate the World's Progress on Nutrition. Washington, DC: International Food Policy Research Institute.

6. De Onis M, Brown D, Blossner M et al. (2012) Levels and trends in child malnutrition. UNICEF-WHO-The World Bank joint child malnutrition estimates. Geneva: World Health Organization.

7. UBOS (2012) Uganda Demographic and Health Survey 2011. Kampala: Uganda Bureau of Statistics.

8. Namugumya B, Sethuraman K, Elisabeth A et al. (2014) Reducing Malnutrition in Uganda: Estimates to Support Nutrition Advocacy Uganda PROFILES 2013. Washington DC and Kampala: FHI360/ FANTA and Office of the Prime Minister of Uganda.

9. UBOS (2013) Addendum to Chapter 11 of the Uganda Demographic and Health Survey: Vitamin A Defficiency Results. Kampala: Uganda Bureau of Statistics.

10. FANTA-2 (2010) Analysis of the nutrition situation in Uganda. Washington DC: USAID Food and Nutrition Technical Assistance II Project, AED.

11. Bachou H, Labadarios D (2002) The nutrition situation in Uganda. Nutrition 18, 356-358.

12. Harvey P, Rambeloson Z, Dary O (2010) The 2008 Uganda Food
Consumption Survey: Determining the dietary patterns of Ugandan women and children. Washington DC: A2Z: The USAID Micronutrient and Child Blindness Project, AED

13. WFP, UNECA, AUC (2013) The cost of hunger in Uganda: implications on national development and prosperity. Kampala: World Food Programme, United Nations Economic Commission for Africa and the African Union Commission.

14. Benson T, Mugarura S, Wanda K (2008) Impacts in Uganda of rising global food prices: the role of diversified staples and limited price transmission. Agr Econ 39, 513-524.

15. FAO (1996) Declaration on World Food Security. World Food Summit. Rome: Food and Agriculture Organization of the United Nations.

16. Webb P, Coates J, Frongillo EA et al. (2006) Measuring household food insecurity: why it's so important and yet so difficult to do. J Nutr 136, 1404S-1408S.

17. FAO, IFAD, WFP (2015) The State of Food Insecurity in the World. Meeting the 2015 international hunger targets: taking stock of uneven progress. Rome: The Food and Agriculture Organization of the United Nations.

18. UBOS (2016) The National Population and Housing Census 2014 - Main Report. Kampala: Uganda Bureau of Statistics.

19. SCN (2011) $6^{\text {th }}$ report on the world nutrition situation: progress in nutrition. Geneva: United Nations System Standing Committee on Nutrition.

20. UBOS (2007) Uganda Demographic and Health Survey report. Kampala: Uganda Bureau of Statistics and Macro-DHS Inc.

21. MFPED (2013) The Background to the Budget 2013/2014 Fiscal Year. The Journey Continues: Towards Social Economic Transformation. Kampala: Uganda's Ministry of Finance, Planning and Economic Development.

22. FAO, IFAD, WFP (2013) State of Food Insecurity in the World 2013. The Multiple dimensions of food security. Rome: Food and Agriculture Organization of the United Nations.

23. Kikafunda JK, Walker AF, Collett D et al. (1998) Risk factors for early childhood malnutrition in Uganda. Pediatrics 102, E45.

24. Turyashemererwa FM, Kikafunda J, Annan R et al. (2013) Dietary patterns, anthropometric status, prevalence and risk factors for anaemia among school children aged 5-11 years in Central Uganda. J Hum Nutr Diet 26 Suppl 1, 73-81.

25. GOU (2011) Uganda Nutrition Action Plan 2011-2016. Kampala: National Planning Authority, Government of Uganda.

26. Kikafunda JK, Tumwine JK (2006) Diet and socio-economic factors and their association with the nutritional status of pre-school children in a low income suburb of Kampala City, Uganda. East Afr Med J83, 565-574.

27. Kavishe B, Biraro S, Baisley K et al. (2015) High prevalence of hypertension and of risk factors for non-communicable diseases (NCDs): a population based cross-sectional survey of NCDS and HIV infection in Northwestern Tanzania and Southern Uganda. BMC Med 13, 126. 28. WHO (2016) Global report on diabetes. Geneva: World Health Organization.
Online ISSN: 2377-0619

Journal Title: International Journal Food and Nutritional Science Journal Short Name: Int J Food Nutr Sci
Ommega Online Publishers

E-mail: foodscience@ommegaonline.org

Website: www.ommegaonline.org 